\title{
Envolvimento dos discentes nas atividades escolares em tempos de pandemia do COVID-19: Ações desenvolvidas pelo o IFPA - Campus Paragominas
}

Involvement of students in school activities in times of COVID-19 pandemic: Actions developed by the IFPA - Campus Paragominas

Participación de los estudiantes en las actividades escolares en tiempos de la pandemia COVID-19: Acciones desarrolladas por el IFPA - Campus Paragominas

Recebido: 02/03/2021 | Revisado: 07/03/2021 | Aceito: 10/03/2021 | Publicado: 19/03/2021

Mário Sérgio de Oliveira Paz

ORCID: https://orcid.org/0000-0003-3086-6932 Instituto Federal de Educação, Ciência e Tecnologia do Pará, Brasil E-mail: mario.paz@ifpa.edu.br

Núbia Regia de Almeida

ORCID: https://orcid.org/0000-0002-5235-7146 Instituto Federal de Educação, Ciência e Tecnologia do Pará, Brasil E-mail: nubia.almeida@ifpa.edu.br

Jaqueline Pereira de Araújo ORCID: https://orcid.org/0000-0003-0538-1490 Instituto Federal de Educação, Ciência e Tecnologia do Pará, Brasil E-mail: jaqueline.araujo@ifpa.edu.br

Ayrton Moraes Ramos

ORCID: https://orcid.org/0000-0001-7894-7614 Instituto Federal de Educação, Ciência e Tecnologia do Pará, Brasil E-mail: ayrton.moraes@ifpa.edu.br

\begin{abstract}
Resumo
Em virtude do isolamento social decorrente da pandemia provocada pelo COVID-19, a comunidade acadêmica do Instituto Federal do Pará (IFPA) do campus Paragominas elaborou estratégias remotas para minimizar as perdas da rotina estudantil com a suspensão de atividades presenciais. Nesse contexto, este artigo visa apresentar as ações didático-pedagógicas que proporcionaram o engajamento dos discentes matriculados na instituição. As atividades de caráter interativo e elucidativo no âmbito científico, artístico, cultural e social iniciaram em maio de 2020. Essas foram conduzidas através das redes sociais facebook, instagram do campus e pela plataforma digital Google Meet. As práticas pedagógicas realizadas possibilitaram o estímulo, o diálogo com os estudantes e a produção de conhecimento. Palavras-chave: Ensino; Estratégias remotas; IFPA; Engajamento; Discentes.
\end{abstract}

\begin{abstract}
Due to the social isolation resulting from the pandemic caused by COVID-19, the academic community of the Federal Institute of Pará (IFPA) on the Paragominas campus developed remote strategies to minimize the losses of the student routine with the suspension of classroom activities.In this context, this article aims to present the didactic-pedagogical actions that provided the engagement of students enrolled in the institution. The activities of an interactive and elucidative character in the scientific, artistic, cultural and social scope started in may 2020. These were conducted through the social networks facebook, instagram on campus and the digital platform Google Meet. The pedagogical practices carried out made it possible to stimulate, dialogue with students and the production of knowledge.
\end{abstract}

Keywords: Teaching; Remote strategies; IFPA; Engagement; Students.

\section{Resumen}

En virtud del aislamiento social derivado de la pandemia provocada por el COVID-19, la comunidad académica del Instituto Federal de Pará (IFPA) del campus Paragominas elaboró estrategias remotas para minimizar las pérdidas de la rutina estudiantil con la suspensión de las actividades presenciales. En este contexto, este artículo busca presentar las acciones didáctico-pedagógicas que proporcionaron el compromiso de los estudiantes matriculados en la institución. Las actividades de carácter interactivo y esclarecedor en el ámbito científico, artístico, cultural y social iniciaron en mayo de 2020. Estos se llevaron a cabo a través de las redes sociales facebook, instagram del campus y la plataforma digital Google Meet. Las prácticas pedagógicas realizadas posibilitaron el estímulo, el diálogo con los estudiantes y la producción de conocimiento.

Palabras-clave: Ensenãnza; Estrategias remotas; IFPA; Compromiso; Estudiantes. 


\section{Introdução}

A Organização Mundial da Saúde (OMS) declarou, em março de 2020, que o mundo passava por uma pandemia. O alto poder de contágio do vírus COVID-19 e o elevado índice de óbitos em todo o mundo impuseram imediatamente a humanidade a um novo ritmo configurado pelo distanciamento social (WHO, 2020). Os setores tradicionalmente organizados em razão de atividades coletivas foram bastante afetados, como é o caso da educação com a suspensão das aulas. No entanto, não demoraram as discussões a respeito da necessidade de dar continuidade ao processo educacional no contexto pandêmico, e principalmente, de como seria possível oferecer estratégias emergenciais à distância para envolver os discentes. Diante dessa situação, Gallo (2008) sugere que a escola reconfigure a rotina pedagógica conciliando as ferramentas tecnológicas disponíveis e extraindo possibilidades e criatividade.

Em termos normativos, a Lei de Diretrizes e Bases da Educação Nacional (LDB) preconiza no artigo 32, que em situações emergenciais a modalidade de ensino remoto pode ser utilizada como complementação da aprendizagem (Brasil, 1996). Com o advento da pandemia, as escolas brasileiras em busca de soluções imediatas para manter as aulas e os vínculos com os estudantes aderiram essa modalidade. De acordo com Pimentel \& Carvalho (2020) o ensino remoto é considerado uma abordagem didático-pedagógica em que os ambientes virtuais são espaços para execução de estratégias de integração dos discentes no âmbito escolar e de produção de conhecimentos. Santos (2020) afirma que esse ensino tem permitido encontros afetuosos e boas dinâmicas curriculares favorecendo o processo de aprendizagem dos alunos. Entretanto, é importante ressaltar que a utilização do ensino remoto, imposto pelo COVID-19, não é um processo simples, pois segundo Santos (2006) a escola ainda tem um currículo e metodologias predominantemente tradicionais. No contexto atual, essa modalidade tem encontrado vários desafios, entre eles: o desenvolvimento de estratégias por parte dos profissionais da educação, adequações a nova rotina por parte dos discentes e familiares, a questão da evasão dos alunos e o uso de tecnologias disponíveis (Souza, 2020).

As ações educativas remotas são consideradas uma espécie de rearranjo das técnicas e recursos. Ademais, para utilizálas não basta somente o domínio das ferramentas de apoio tecnológico, mas, que o professor consiga adequar sua experiência pedagógica presencial a didática virtual. Isso auxiliará na mediação com os estudantes e com o uso das mídias digitais Souza (2020). Para Rothen, et al., (2020) o processo educativo pode ocorrer de diversas formas, em múltiplos espaços, cenários e metodologias diversas. A utilização dos recursos com ferramentas disponíveis em ambientes digitais atende públicos e propostas pedagógicas diferenciadas e específicas, tendo como suporte a construção de cenários de aprendizagens e contextos diversos com uso de planejamentos que atendem as características dos tempos emergenciais. Behrens (2009) ressalta a importância de apropriar-se de novas estratégias de ensino capazes de desenvolver nos estudantes habilidades para processar as informações significativas, organizá-las e utilizá-las coerentemente. Para a autora, o grande desafio dos profissionais da educação é selecionar estratégias pedagógicas que possam despertar nos discentes valores éticos e emocionais voltados à solidariedade, perpetuação da paz, sensibilidade e espírito coletivo.

A pandemia do COVID-19 mostrou que a educação precisa ser reinventada e que o ensino conteudista e instrucionista deve ser repensado no espaço escolar. Nessa atual conjectura, é fundamental experimentar outras metodologias e práticas que levem em conta o potencial das tecnologias digitais em rede e favoreçam a colaboração, a autonomia, a criatividade e a autoria de professores e estudantes (Melo, et al., 2021; Nunes, 2021; Souza, 2020).

Em relação ao paradigma educacional local na cidade de Paragominas/PA, destaca-se o Instituto Federal do Pará (IFPA) campus Paragominas que através do ensino, pesquisa, extensão e inovação tecnológica abrange os diversos níveis da educação profissional e tecnológica, desde a básica à pós-graduação. O campus supracitado oferece uma educação pública, gratuita e de excelência aos 619 alunos, matriculados em 2020, distribuídos nos cursos Técnicos em Informática Integrado ao Ensino Médio (IEM), em Meio Ambiente IEM, em Redes de Computadores IEM na modalidade de Educação de Jovens e Adultos (EJA), em Administração Subsequente ao Ensino Médio (SEM), em Redes de Computadores SEM, em Instrumento 
Musical SEM, e, Pós-graduação em Educação do Campo. No contexto pandêmico, as aulas presenciais do campus foram inicialmente suspensas em 18 de março de 2020, conforme a Portaria $N^{\circ} 456 / 2020 / G A B$, seguindo a determinação do Ministério da Educação (MEC). Em 15 de maio de 2020 o Conselho Superior do IFPA emitiu a Resolução N $^{\circ}$ 97/2020/CONSUP suspendendo as atividades escolares por tempo indeterminado.

O IFPA campus Paragominas acreditando na continuidade da formação integral de alunos críticos e autônomos se mostra aberto para experimentar outras metodologias que produzam uma realidade diferente das práticas hegemônicas, inventando novos modos de aprender e de ensinar. O conhecimento, nesse sentido, não se situa na lógica da transmissão e acumulação de informações, mas na produção de outra realidade favorecendo a autoria, o diálogo e o movimento dos estudantes por diversos espaços virtuais. Nessa perspectiva, o objetivo precípuo desse trabalho é mostrar as estratégias que promoveram o engajamento remoto dos discentes da instituição supracitada nas atividades escolares.

\section{Metodologia}

Este trabalho trata-se de um estudo de caso descritivo, de natureza qualitativa e do tipo relato de experiência no campo educacional. Para Pereira, et al., (2018) esse tipo de estudo possui uma riqueza de informações de modo a contribuir com o saber na área de conhecimento no qual for utilizada. De acordo com Silva \& Menezes (2000), a pesquisa descritiva mostra as características de determinada população ou estabelecimento de relações entre variáveis. Vieira \& Zouain (2005) afirmam que a qualitativa atribui importância fundamental aos depoimentos dos atores sociais envolvidos, aos discursos e aos significados, descrevendo de forma detalhada fenômenos e elementos que o envolve.

Passado o primeiro impacto imposto pela situação emergencial da pandemia do COVID-19, a gestão do campus realizou reuniões virtuais com a comunidade acadêmica para discutir, elaborar e viabilizar propostas de atividades escolares remotas para a integração dos estudantes. As ações didático-pedagógicas foram organizadas e conduzidas on line através das redes sociais oficiais facebook, Instagram do IFPA campus Paragominas e pela plataforma Google Meet. Essas começaram a ser executadas no início do mês do maio de 2020 trazendo novas formas de interagir com o outro, manter-se conectado para avivar as esperanças de dias melhores, e, amenizar o impacto do distanciamento social.

O primeiro momento de integração foi através de um encontro virtual, no período noturno com duração de 2 horas de modo informativo. Em seguida, os discentes foram orientados e convidados a participar das ações pedagógicas emergenciais remotas de engajamento.

As estratégias seguintes foram de caráter interativo e elucidativo com atividades literárias, artísticas e culturais, respectivamente. O campo literário abordou apresentações elucidativas sobre diversos clássicos da literatura através de encontros síncronos. Foi realizado uma comemoração do São João virtual e dois concursos on line, um de fotografias e vídeos sob o aspecto artístico e cultural junino e outro de produção textual de poemas. Além disso, foram estabelecidos mecanismos de escuta e acompanhamento contínuo dos estudantes através das redes sociais. Nesse sentido, a equipe pedagógica e diretiva do IFPA utilizou-se da tecnologia aliada ao conhecimento científico para permitir a interação e acesso dos alunos aos conteúdos e propostas de atividades, convergindo com Pereira, et al., (2018) quando enfatizam o uso da mídia digital como elemento relevante na produção de novos conhecimentos.

\section{Resultados e Discussão}

Em decorrência da suspensão das atividades presenciais de Ensino, Pesquisa e Extensão do Instituto Federal do Pará (IFPA) - Campus Paragominas, causada pela pandemia da Covid-19, a comunidade acadêmica elaborou estratégias para promover o engajamento remoto dos discentes nas atividades escolares do campus. A Figura 1 apresenta as ações organizadas. 
Figura 1 - Ações para integração dos alunos do IFPA - campus Paragominas com o advento da pandemia.

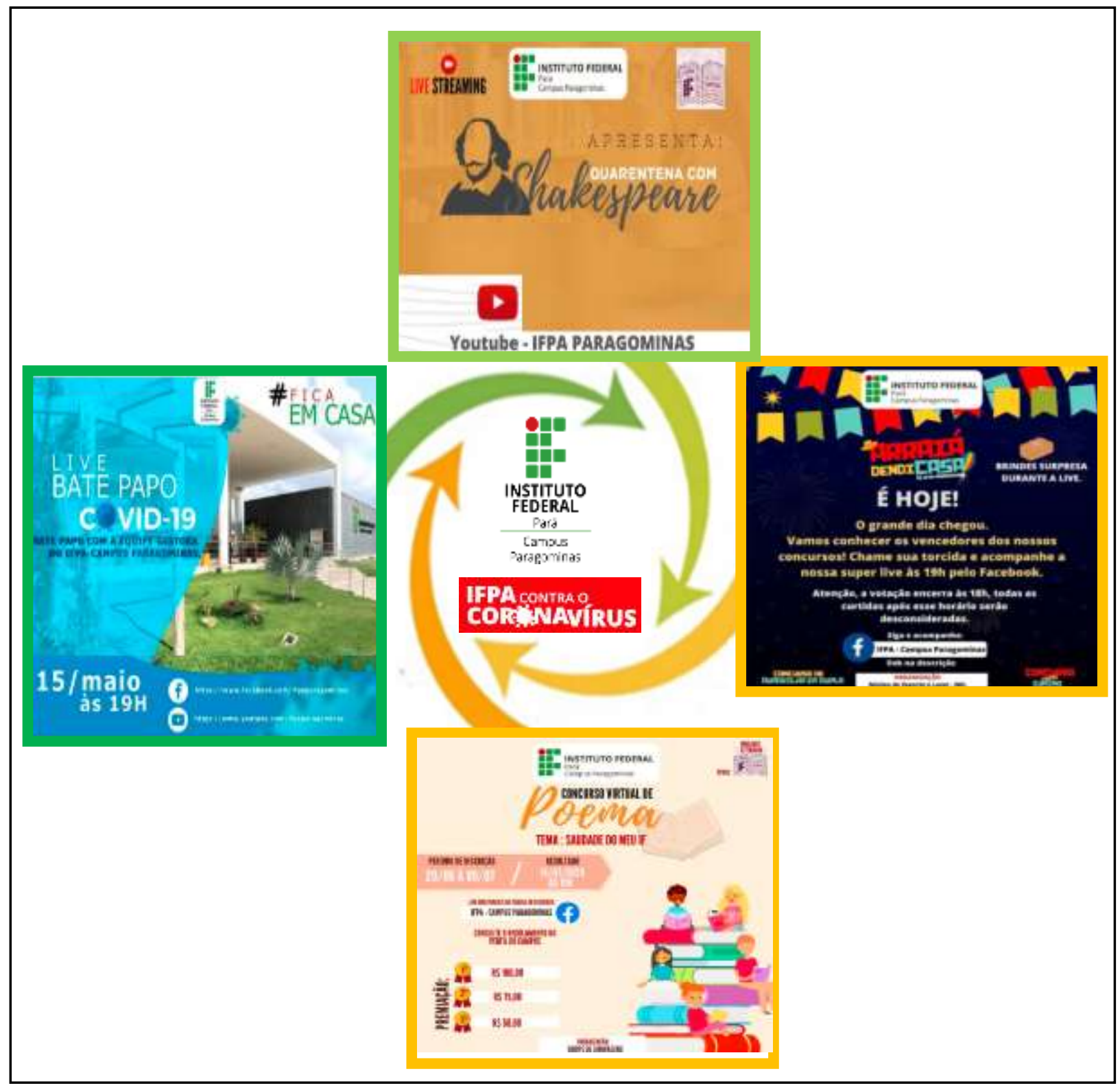

Fonte: Autores (2021).

As rápidas mudanças impressas pela pandemia na rotina mundial, reconfigurada diariamente, evidenciaram a importância da comunicação informativa como ponto de ação inicial para viabilizar o envolvimento dos alunos nas atividades escolares. Segundo Moresi (2000) a informação é geradora do conhecimento, elemento fundamental responsável por conduzir a tomada de decisão. Nesse sentido, o encontro realizado pela comunidade acadêmica do campus Paragominas, através da rede social do facebook do IFPA, trouxe orientações aos estudantes sobre a pandemia, destacando os aspectos científicos, econômicos e sociais. Essa ação como instrumento integrador foi conduzida pelos professores com formação em biologia que promoveu um bate papo explicativo com os alunos destacando principalmente as formas de transmissão, os fatores de risco e as medidas de prevenção do novo Coronavírus. Na finalização desse encontro, os docentes e a gestão incentivaram os alunos à participação das atividades estudantis remotas propondo o estabelecimento de uma nova rotina escolar e assegurando um apoio à saúde emocional dos discentes mediante ao distanciamento social e a interrupção das aulas presenciais por causa da emergência sanitária. A repercussão positiva dessa ação culminou em um feed back dos alunos através de manifestações via 
mensagens nas redes sociais oficiais do Campus, qualificadas como motivacionais em relação ao contato com o campus e esclarecedoras sobre a situação pandêmica.

A segunda ação de envolvimento foi elaborada pelos docentes que integram o Projeto de Extensão Mosaico Literário que exploraram apresentações elucidativas sobre grandes obras literárias destacando as de Shakespeare. Essa atividade buscou aguçar a curiosidade e o interesse pela leitura de tais literaturas. De acordo com os Parâmetros Curriculares Nacionais um dos papéis da escola é formar leitores que contextualizem e que mantenham uma relação crítica e opinativa com o que está sendo lido (Brasil, 1998). Nesse sentido, a ação supracitada promoveu um evento intitulado como "Todo leitor tem seu personagem preferido" em que os estudantes se caracterizaram de um personagem literário e através de um momento virtual contextualizaram sobre as obras literárias lidas. Segundo Todorov (2009) essa estratégia proporcionou um meio mais efetivo de aprendizado com diferentes formas, pensamentos e ideias, e, de interiorização de conhecimento a um nível satisfatório de compreensão entre os alunos.

Moreira e Candau (2003) enfatiza a relação intrínseca existente entre cultura e a educação no processo de aprendizagem e nas práticas pedagógicas. O campus Paragominas reconhecendo essa interligação como essencialmente característica do universo educacional elaborou a terceira estratégia de engajamento remoto dos alunos. A ação organizada pelo Núcleo de Esporte e Lazer promoveu um evento virtual pela página oficial do campus na rede social Instagram denominado "O arraiá dendi casa do IFPA campus Paragominas" visando manter a tradição da escola em comemorar as festividades juninas. Esse momento contemplou um concurso com premiações que possibilitou a integração efetiva dos alunos através do envio de fotografias e vídeos trajados com figurinos juninos para rede social. Além de se constituir uma atividade lúdica, o evento foi utilizado como um instrumento pedagógico, uma vez que os professores forneceram aos alunos conteúdos educativos relacionados à temática, ressaltando a importância das atividades dos cidadãos rurais para a sociedade como um todo. Isso permitiu a socialização dos discentes, o fortalecimento das relações socioculturais e a disseminação de conhecimento em relação aos elementos históricos, religiosos e mitológicos que envolvem a manifestação cultural.

Sabendo que a escola não é um espaço de mera transmissão de conteúdos ou de preparação para a vida adulta, mas também de convivência e de organização social, o isolamento social e o prolongamento da pandemia motivaram os docentes a interagir com os estudantes buscando oportunizar a socialização das percepções dos alunos frente às implicações da pandemia, sobretudo a interrupção da rotina escolar. Os professores da disciplina de Linguagens com o apoio do Projeto de Extensão Mosaico Literário e das demais equipes do campus promoveram o I Concurso Virtual de Poema com o tema "Saudade do meu $I F$ " buscando explorar a escrita associada ao âmbito emocional e afetivo dos discentes. Esse concurso rendeu várias produções textuais que foram socializadas nas redes sociais do campus. De acordo com os Parâmetros Curriculares Nacionais de Língua Portuguesa a construção de textos fortalece o senso crítico e dá sentido a leitura (Brasil, 2001). Assim, o instrumento estratégico utilizado amparado na escrita possibilitou a transmissão de ideias, sentimentos e percepções dos alunos, além de estimular o processo educativo do binômio leitura e escrita.

Em virtude da pandemia, o Ministério da Educação homologa e declara como legal a carga horária de atendimento remoto na rotina diária das instituições de ensino (Brasil, 2020). Baseado nessa configuração, o sistema educacional processase por aulas em tempo real (síncronas), diretamente entre professor e aluno, quanto por aulas gravadas (assíncronas), com a exibição do material para a turma, disponibilizado por meio de plataformas tecnológicas. Soma-se a isso, a modalidade de atendimento personalizado à distância, com atenção individual aos alunos (Souza, et al., 2021). Tomando como base esse atendimento remoto, o campus Paragominas vem promovendo a assistência aos estudantes com ações integradoras do processo de ensino aprendizagem, auxílio ao planejamento da rotina de estudos e fortalecimento das relações entre os alunos e docentes, gestão e demais equipes do campus. 


\section{Considerações Finais}

Pode-se inferir que a busca por adequações das práticas pedagógicas no IFPA campus Paragominas, em um período de pandemia marcado pela suspensão das aulas presenciais, trouxe a possibilidade de construir novas rotinas na tentativa de mitigar as perdas educacionais locais para os alunos. Além disso, observou-se que as estratégias desenvolvidas estimularam a interação e o diálogo com os discentes tornando o ambiente escolar mais presente.

A execução das ações desenvolvidas para o engajamento dos alunos do campus deverá intensificar as mudanças que já estavam ocorrendo com o uso das tecnologias e a possível propagação de um ensino híbrido. Nesse sentido, é relevante que as experiências e os novos artifícios pedagógicos colocados em prática emergencialmente sejam socializados e apresentados os resultados, para que com isso, sejam discutidas suas potencialidades e desafios.

As atividades desenvolvidas são instrumentos que podem viabilizar diversos trabalhos nessa nova configuração vivenciada na educação. Como propostas para futuras pesquisas, sugere-se realizar um diagnóstico on line para saber quais são os interesses e necessidades dos estudantes em cada componente curricular e utilizar os resultados como base para o planejamento docente pontual no processo de ensino e aprendizagem na modalidade híbrida, e, avaliar o uso efetivo de metodologias virtuais atrativas e ativas nas diversas disciplinas do ensino médio no campus Paragominas com foco no desempenho escolar do aluno.

\section{Agradecimentos}

Os autores deste artigo são membros do Grupo de Pesquisa: Multidisciplinar em Ensino, Educação, Química, Linguagens e Meio Ambiente - IFPA - Campus Paragominas, e agradecem-no pelo apoio e o incentivo à pesquisa.

\section{Referências}

Beherens, M. (2009). Paradigma emergente e a prática pedagógica. Vozes.

Brasil, (1996). Ministério da Educação. Lei de Diretrizes e Bases da Educação Nacional. Lei $n^{\circ} 9.394$ de 20 de dezembro de 1996. Estabelece as diretrizes e bases da educação nacional. http://portal.mec.gov.br/seesp/arquivos/pdf/lei9394_1dbn1.pdf

Brasil, (1998). Ministério da Educação. Parâmetros Curriculares Nacionais: língua portuguesa. Brasília: MEC. http://basenacionalcomum.mec.gov.br/images/pcn/portugues.pdf

Brasil, (2020). Ministério da Educação. Conselho Nacional de Educação. Parecer CNE/CPN. 5/2020 de 28 de abril de 2020 . Reorganização do Calendário Escolar e da possibilidade de cômputo de atividades não presenciais para fins de cumprimento da carga horária mínima anual, em razão da Pandemia da COVID-19. http://portal.mec.gov.br/index.php?option=com_docman\&view=download\&alias=14511-pcp005-20\&category_slud=marco-2020pdf\&Itemid=30192

Gallo, S. (2008). Deleuze e a educação. Autêntica. 18(1), 79-82. file://C:/Users/andre/Downloads/532-2508-1-PB.pdf

Melo, C. B., Farias, G. D., Nunes, V. R. R., Andrade, T. S. A. B. \& Piagge, C. S. L. D. (2021). A extensão universitária no Brasil e seus desafios durante a pandemia da COVID-19. Research, Society and Development, 10(3), 1-12. http://dx.doi.org/10.33448/rsd-v10i3.12991

Moreira, A. F. B. \& Candau, V. M. (2003). Educação escola e Cultura(s): construindo caminhos. Revista Brasileira de Educação. (23), 156 -168. https://www.scielo.br/pdf/rbedu/n23/n23a11.pdf

Moresi, E. A. D. (2000). Delineando o valor do sistema de informação de uma organização. Ciência da Informação. 29(1), 14-24. https://www.scielo.br/pdf/ci/v29n1/v29n1a2.pdf

Nunes. R. C. (2021). Uma visão geral da evasão de estudantes universitários durante os estudos remotos provocados pela pandemia do COVID-19. Research, Society and Development, 10(3), 1-13. http://dx.doi.org/10.33448/rsd-v10i3.13022

Pereira, A.S., Shitsuka, D. M., Parreira, F. J. \& Shitsuka, R. (2018). Metodologia da pesquisa científica. UFSM.

Pimentel, M. \& Carvalho, F. S. P. (2020). Princípios da Educação Online: para sua aula não ficar massiva nem maçante! SBC Horizontes. http://horizontes.sbc.org.br/index.php/2020/05/principios-educacao-online/

Rothen, J. C., Nóbrega, E. C. \& Oliveira, I. S. (2020). Aulas Remotas em Tempo Emergente: Relato de experiência com a turma “Avaliação Institucional da Educação" na UFSCar. Cadernos da Pedagogia, 14(29) (Edição Especial), 97-107. http://www.cadernosdapedagogia.ufscar. br/index.php/cp/article/view/1441 
Research, Society and Development, v. 10, n. 3, e36310313470, 2021

(CC BY 4.0) | ISSN 2525-3409 | DOI: http://dx.doi.org/10.33448/rsd-v10i3.13470

Santos, B. S. (2006). A Gramática do Tempo: para uma nova cultura política. Editora Cortez.

Santos, E. (2020). EAD, palavra proibida. Educação online, pouca gente sabe o que é. Ensino remoto, o que temos para hoje. Mas qual é mesmo a diferença? Revista Docência e Cibercultura. https://www.e-publicacoes.uerj.br/index.php/re-doc/index

Silva, E. L. \& Menezes, E. M. (2000). Metodologia da pesquisa e elaboração de dissertação. Florianópolis: UFSC/ PPGEP/LED. http://cursos.unipampa.edu.br/cursos/ppgcb/files/2011/03/Metodologia-da-Pesquisa-3a-edicao.pdf

Souza, E. P. (2020). Educação em tempos de pandemia: desafios e possibilidades. Caderno de Ciências Socias Aplicadas. Ano XVII, 17. https://doi.org/10.22481/ccsa.v17i30.7127

Souza, K. R., Santos, G. B., Rodrigues, A. M. S., Felix, E. G., Gomes, L., Rocha, G. L., Conceição, R. C. M., Rocha, F.S. \& Peixoto, R. B (2021). Trabalho remoto, saúde docente e greve virtual em cenário de pandemia. Trabalho, Educação e Saúde, 19. http://dx.doi.org/10.1590/1981-7746-sol00309

Todorov, T. (2009). A Literatura em Perigo. Tradução: Caio Meira. Difel.

Vieira, M. M. F. \& Zouain, D. M. (2005). Pesquisa qualitativa em administração: teoria e prática. Editora FGV.

WHO, (2020). World Health Organization. https://www.who.int/emergencies/diseases/novel-coronavirus-2019 